\title{
Synthesis, Properties and Potential Applications of Porous Graphene: A Review
}

\author{
Paola Russo ${ }^{1,2,3}$, Anming $\mathrm{Hu}^{1,3, *}$, Giuseppe Compagnini ${ }^{2}$
}

(Received 10 September 2013; accepted 24 October 2013; published online 8 November 2013)

\begin{abstract}
Since the discovery of graphene, many efforts have been done to modify the graphene structure for integrating this novel material to nanoelectronics, fuel cells, energy storage devices and in many other applications. This leads to the production of different types of graphene-based materials, which possess properties different from those of pure graphene. Porous graphene is an example of this type of materials. It can be considered as a graphene sheet with some holes/pores within the atomic plane. Due to its spongy structure, porous graphene can have potential applications as membranes for molecular sieving, energy storage components and in nanoelectronics. In this review, we present the recent progress in the synthesis of porous graphene. The properties and the potential applications of this new material are also discussed.
\end{abstract}

Keywords: Graphene; Porous graphene; Gas separation; Energy storage

Citation: Paola Russo, Anming $\mathrm{Hu}$ and Giuseppe Compagnini, "Synthesis, Properties and Potential Applications of Porous Graphene: A Review", Nano-Micro Lett. 5(4), 260-273 (2013). http://dx.doi.org/10. 5101/nml .v5i4.p260-273

\section{Introduction}

Graphene, a two-dimensional (2D) sheet of $\mathrm{sp}^{2}$ hybridized carbon atoms, initially as a theoretical model for many years, was employed for describe the properties of other carbon-based materials [1]. However, in 2004, Geim and Novoselov experimentally produced graphene sheets by mechanical exfoliation of graphite [2], and the unique properties displayed by this material, immediately bring it onto the focus of scientific research [3-5]. During the past years, different fabrication techniques have developed for the synthesis of graphene. For instance, it can be grown by chemical vapor deposition (CVD) [6-8], produced by the liquid phase exfoliation of graphite [9], thermal exfoliation of graphite [10], and ultrasonic dispersion of graphitic oxide [11]. All these investigations aim to finding a suitable technique for a large-scale production $[2,3,12]$. Currently, it is necessary to compare these methods, review their advantages and drawbacks, and thereby develop a novel method for large-scale production.

The synthesis is correlated to the outstanding properties of graphene. For instance, due to its unique edge atomic configuration and electronic band structures, graphene exhibits novel transport effects, such as the ambipolar field effect and minimum conductivity that lead to exceptional transport properties such as quantum Hall effects, and a high mobility of carriers $[2,14,15]$. It was reported that by modifying the structure of graphene (basal planes or edges) it is possible to tailor the graphene properties and produce new types of graphene-based materials, which can be employed for the design of nanoscale transistors [16], gas sensors [2], fuel cells [17], solar cells [18], organic light-emitting diodes (OLEDs) displays $[19,20]$, and bio-related sensors [21]. Recently, porous graphene (PG), a graphenebased material, is attracting the interest of many researchers. This material can be described as a graphene

\footnotetext{
${ }^{1}$ Department of Mechanical and Mechatronics Engineering, University of Waterloo, 200 University Ave. West Waterloo, Ontario N2L 3G1, Canada

${ }^{2}$ Dipartimento di Scienze Chimiche, Università degliStudi di Catania, Viale Andrea Doria 6, Catania, 95125, Italy.

${ }^{3}$ Institute of Laser Technology, Beijing University of Technology, 100 Pingle Yuan, Haidian District, Beijing 100022, P. R. China

*Corresponding author. E-mail: anminghu@bjut.edu.cn
} 
sheet with some carbon atoms vacancies (holes/pores) in the plane. Generally, porous materials contain holes either with random or high regularity. Depending on their diameters, the pores can be classified in micropores (diameters below $2 \mathrm{~nm}$ ), mesopores in the range 2-50 nm, and for diameters above $50 \mathrm{~nm}$, the pores are labeled macropores [22]. Porous carbons are the most employed porous materials, for their high surface areas, hydrophobic nature, and low cost manufacture. They are of great interest, due to their applications in water and air purification. In particular, the porous carbons with micropores are used as molecular sieves and catalyst [23]. While, the ones displaying mesopores and macropores, are usually employed for the adsorption of large hydrophobic molecules, for chromatographic separations and electrochemical capacitors [24]. Porous carbons are usually obtained via carbonization of precursors, followed by activation [25]. Recently, the possibility of using graphene as membrane for gas purification, or for the gas storage, has been located at the spotlight of latest energy-related research $[26,27,15]$. In particular, researchers are studying different approaches for the synthesis of the PG. As aforementioned, PG is a graphene sheet with micropores originating from the removal of some $\mathrm{sp}^{2}$ carbon atoms from the plane. Due to the spongy structure of this material, PG has been suggested as a suitable membrane for gas separation $[28,29]$, energy storage $[30,31]$, and as a basic material in nanoelectronics applications $[32,33]$.

In this brief review, the technique employed so far for the synthesis of porous graphene will be summarized and discussed with some of its applications. This paper is organized as follows: following the discussion of the scientific signification of porous graphene in the first section, the mechanical and electronic properties will be discussed in the second section, while the main synthetic approaches will be presented in the third one. In the last section, the potential applications of porous graphene will be described. This article is intended to be a useful primer to researchers who are exploring porous graphene as options for innovative materials and functional components for catalysis, energy and nanoelectronics, developing other new applications, such as biomedical and biosensing devices.

\section{Properties of porous graphene}

\section{Microstructure}

Porous graphene is a modified graphene sheet, where the absence of carbon atoms within the plane creates some holes/pores. Recently, Bieri and coworkers [34] produced a form of porous graphene, with a regular distribution of the pores. Noteworthy, the authors fabricated a two-dimensional (2D) polyphenylene networks with single-atom wide pores and sub-nanometer period- icity by the aryl-aryl coupling on a metal surface of the cyclohexa-m-phenylene (CHP), used as precursor [34]. The pores in the resulting $2 \mathrm{D}$ polyphenylene are natural and uniformly distributed with the same width and since the structure of the precursor, the CHP, resembles graphene with periodically missing phenyl rings, the structure of porous graphene can be described by employing the structure of the 2D polyphenylene fabricated by Bieri and co-workers. The unit cell of graphene contains two carbon atoms, while for a $2 \mathrm{D}$ polyphenylene layer in a $3 \times 3$ supercell, the unit cell is composed of two $\mathrm{C}_{6} \mathrm{H}_{3}$ rings, which are linked by a C-C bond [35]. As shown in the Fig. 1, the optimized lattice parameter for $2 \mathrm{D}$ polyphenylene is $\mathrm{a}=\mathrm{b}=7.455 \AA$ (which is also the distance between two pores), and agrees well with the experimental value $(7.4 \AA)[34,35]$. The pores of $2 \mathrm{D}$ polyphenylene show an electron-deficient characteristic, the pore is hexagonal in shape, and the width of pore is estimated to be almost $2.48 \AA$ [35].

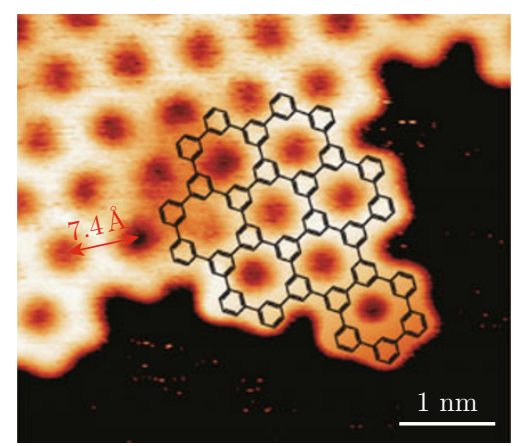

Fig. 1 STM image of 2D polyphenylene, model for porous graphene. Taken from Ref. [34].

\section{Mechanical, chemical and physical properties}

Pure graphene, as aforementioned, displays outstanding properties. For instance, the value of the Young's modulus ranges from $0.5 \mathrm{TPa}$ [36], measured using atomic force microscope (AFM), to 1.0 TPa calculated by Lee et al. [37], who measured the elastic properties and intrinsic breaking strength of freestanding monolayer graphene membranes by nanoindentation with an AFM, and their experiments established graphene as the strongest material ever measured. The in-plane thermal conductivity of graphene at room temperature is among the highest of any known material, about $2000-4000 \mathrm{Wm}^{-1} \mathrm{~K}^{-1}$ for freely suspended samples, even if some works report a value of $\mathrm{K}$ ranging from 600 to $5000 \mathrm{Wm}^{-1} \mathrm{~K}^{-1}$ [38-40]. Porous graphene derives from graphene; therefore, it can take advantage of these properties. In particular, porous graphene can enhance some of graphene performances, since it was reported that the modification of graphene structure could improve its chemical and electronic properties [16-21]. For example, Shao and co-workers reported that nitrogen-doped graphene 
showed a higher electrocatalytic activity toward oxygen reduction and $\mathrm{H}_{2} \mathrm{O}_{2}$ reduction than pure graphene [17]. Consequently, many studies have been conducted on the properties of porous graphene. However, the optimized performance of the resulting materials with adding the modification of graphene sheets has to be controlled. For example, Ha and coworkers reported the effects of chemical modification of graphene on the properties of polyimide/graphene nanocomposites. The authors studied different properties of three materials: pure polyimide (PI), polyimide/graphene oxide (PI/GO) composite and polyimide/reduced graphene oxide (PI/rGO) composite. As regard the mechanical properties, it was shown that the incorporation of a certain amount of GO and rGO into PI films can enhanced their tensile strength and tensile modulus, however if the amount of GO and rGO is increased above a certain value the tensile strength and tensile modulus decreased. In particular, the authors reported that as the GO content increased from $1 \mathrm{wt} \%$ to $5 \mathrm{wt} \%$, the tensile modulus increased from $22.87 \mathrm{GPa}$ to 36.46 $\mathrm{GPa}$, but a GO content of $7 \mathrm{wt} \%$ led to a decrease to $22.32 \mathrm{GPa}$. This decrease in the tensile properties might be due to the increasing aggregation tendency of the GO layers forming some defects in the nanostructure of the nanocomposites. As regard the PI/rGO nanocomposites, these nanocomposites showed significant enhancement in both the tensile strength and tensile modulus when the rGOD content increased from 1 wt $\%$ to $5 \mathrm{wt} \%$, whereas the tensile properties decreased when the filler content is increased to $7 \mathrm{wt} \%$, with a similar trend observed for the GO filler [41]. As the porous graphene is still in its infant stage, the further work is needed to elucidate relative molecular structures, such as, it is unclear the edge state of porous graphene, is in an armchair or a zigzag configuration. However, it displays remarkable features such as a low mass density [42], a large specific surface area (up to $3100 \mathrm{~m}^{2} \mathrm{~g}^{-1}$ ) [43], preferred gas permeability [29], and a higher specific capacitance [44], etc. Consequently, porous graphene has been proposed for various applications, such as gas separation [45-48], energy storage units in lithium batteries and supercapacitors [49,50], and nanoelectronics $[32,33]$. Recently, porous graphene has been reported as an efficient sorbent which removes oil and organic liquid pollution from water $[51,52]$.

\section{Electronic structure}

One of the limitations of pure graphene in nanoelectronics is the lack of a band gap [32,53], which is the defining concept for semiconductor materials and essential for controlling the conductivity by electronic means [53] A material without a band gap is basically metallic, therefore, not suitable for functionally semiconducting components. Therefore, for sev- eral years, researchers studied a way for induce a band gap opening of graphene by doping $[32,53]$, chemical functionalization [54], and introduction of defects and pores [55]. Many computational studies [56-58] demonstrated that the presence of holes/pores within the graphene plane could induce a band opening in graphene. Shown in Fig. 2 is the band structure for graphene and hydrogenated porous graphene (HPG) [56]. For pure graphene the gap value is $0 \mathrm{eV}$, while for porous graphene, De La Pierre and coworkers, found a value of $3.95 \mathrm{eV}$ [56]. The reason why porous graphene has a larger band gap, is due to its peculiar aromatic structure. Resonant $\pi$ bonds are present only inside the benzene-like rings; single C-C bonds that interconnect rings isolate their aromatic units, hindering electron delocalization on the whole structure (contrary to case of graphene) [56]. Depending on the computational methods employed, the band gap values of porous graphene can widely vary. For instance, the density functional theory (DFT) study conducted by Brunetto et al [57] gave a value of $3.3 \mathrm{eV}$ for $\mathrm{HPG}$, which is about $20 \%$ smaller than the results reported by De La Pierre [56]. The reason is due to the fact that, pure generalized gradient approximation (GGA) functions underestimate
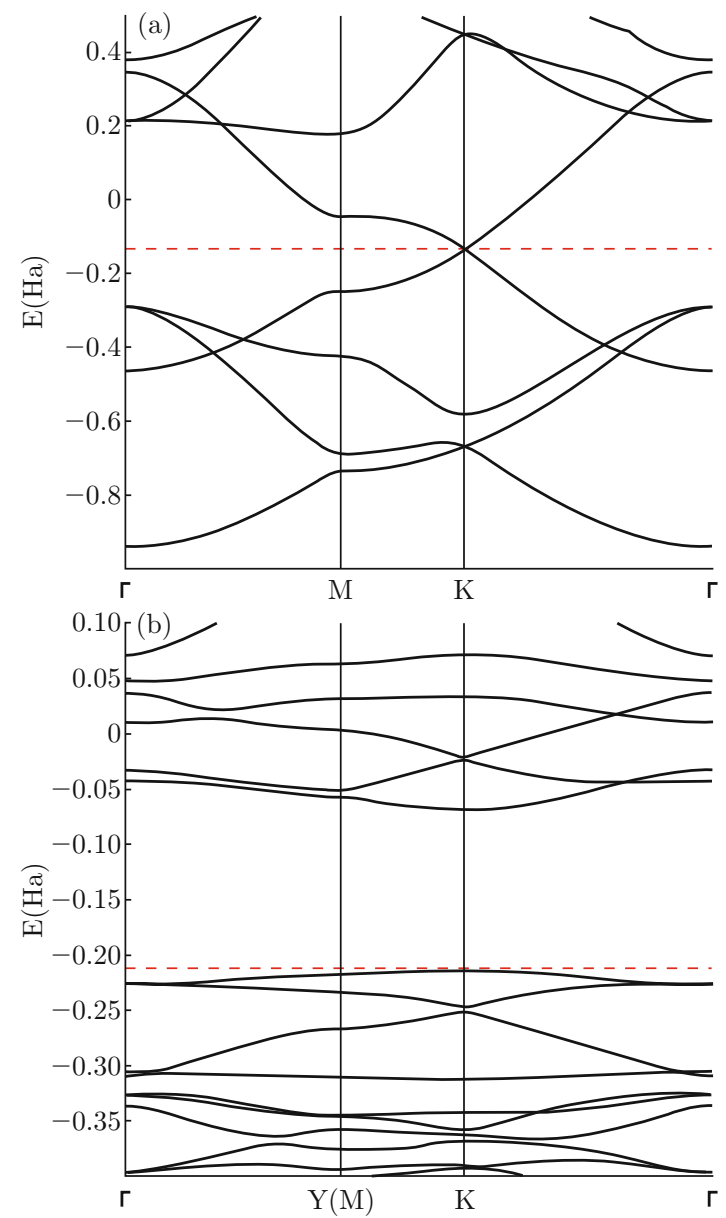

Fig. 2 Computed electronic bands for (a) graphene; (b) HPG [56]. 
experimental band gap values, while hybrid functionals are usually closer to experiments [58]. Du et al. [32] predicted for porous graphene a band gap of $3.2 \mathrm{eV}$, for a calculation with the HSE06 hybrid functional (a functional developed by Heyed, Scuseria, and Ernzerhf). This value becomes smaller, reaching the value of 2.34 $\mathrm{eV}$, when local density approximation (LDA) calculations are employed. Despite these studies show different values of the band gap of porous graphene, the most attractive thing is that the presence of pores induces a band gap opening. In light of these results, many studies have been conducted in order to use porous graphene in nanoelectronics $[32,33]$.

\section{Synthesis of porous graphene}

Porous graphene, as aforementioned, is a graphene sheet, where some carbon atoms in the plane are missing. Therefore, some holes (pores) are created within the plane. The methods employed so far for the synthesis of porous graphene, are summarized below, and involve either physical or chemical approaches.

\section{Modification of suspended graphene sheets by exposure to an electron beam}

Fischbein et al. [59] demonstrated the formation of nanopores in suspended graphene sheets by controlled exposure of the sheets to a focused electron beam of a transmission electron microscope (TEM) apparatus. In that experiment, the graphene samples were prepared by mechanical exfoliation of graphite and then transferred to a $\sim 50 \mathrm{~nm}$-thick suspended SiNx membrane substrate. Before the transfer, the SiNx membrane was patterned with arrays of $\sim 1 \mu \mathrm{m}^{2}$ holes. By increasing TEM magnification and condensing the imaging electron beam to its minimum diameter, $\sim 1 \mathrm{~nm}$, and moving the beam position with the condenser deflectors, the pores were created with a diameter of $3.5 \mathrm{~nm}$, as shown in the Fig. 3. The authors also demonstrated that the porous graphene obtained in such way resulted to be very stable. Moreover, the removal of carbon did not introduce distortions of the graphene sheet, such as folds or wrinkles.

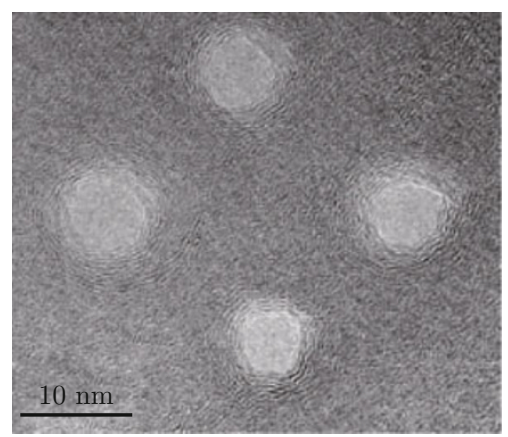

Fig. 3 TEM images of pores created on suspended graphene sheets electron beam ablation adapted from Ref. [59].
Graphene sheets etched with nitrogen in a scanning electron microscope (SEM)

A low-energy focused electron beam in a SEM apparatus with nitrogen gas, successfully produced nanopores of $<10 \mathrm{~nm}$ in size in graphene sheets [60], as shown in Fig. 4. For the preparation of the graphene sheets, graphite was sonicated in isopropanol for $48 \mathrm{~h}$, and after centrifugation, the dispersion was dropped onto a lacey carbon grid and dried naturally. The obtained sample was then placed in a SEM chamber and the electron beam was focused onto the surface of the graphene sheet. The authors found out that, the graphene etching occurred when the electron was focused in the presence of a flux of nitrogen gas, delivered a nozzle inside the SEM chamber. As a consequence, nanopores with a diameter of $<10 \mathrm{~nm}$ were introduced within the graphene plane, and a degradation of the graphene structure occurred leading the introduction of lattice damage and amorphization.

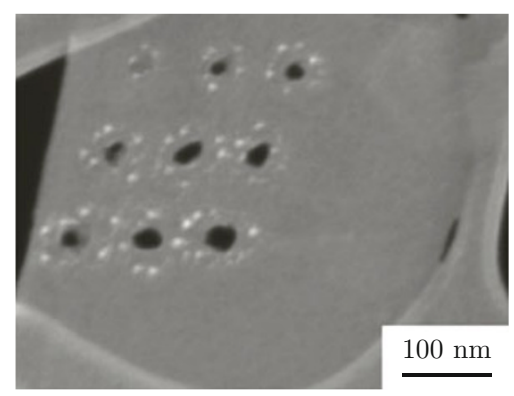

Fig. 4 Nanopores formed in a graphene sheet after nitrogen etching in a SEM apparatus. Adapted from Ref. [60].

\section{Etching of graphene sheets by $\mathrm{MnO}_{2}$}

An example of chemical synthesis of porous graphene is the method reported by Fan et al. [61]. The authors succeeded in the production of porous graphene nanosheets (PGNs) by the etching of carbon atoms on the graphene sheets by $\mathrm{MnO}_{2}$. A scheme of the process developed by Fan is reported in Fig. 5. The starting material was the graphene oxide, synthesized from graphite by a modified Hummers method [62]. In order to obtain the porous graphene, the GO was firstly dispersed in deionized water and the obtained solution was ultrasonicated. The resulting solution was mixed with $\mathrm{KMnO}_{4}$, and then the suspension was heated using a microwave oven. The obtained product was mixed with water and hydrazine solution for reduction of GO. In the last step of the reaction, the product was washed with oxalic acid and hydrochloric acid, water and ethanol, respectively. The reaction that takes place is:

$4 \mathrm{MnO}_{4}^{-}+3 \mathrm{C}+\mathrm{H}_{2} \mathrm{O} \rightleftharpoons 4 \mathrm{MnO}_{2}+\mathrm{CO}_{3}^{2-}+2 \mathrm{HCO}_{3}^{-}$ [Taken from [61]] 


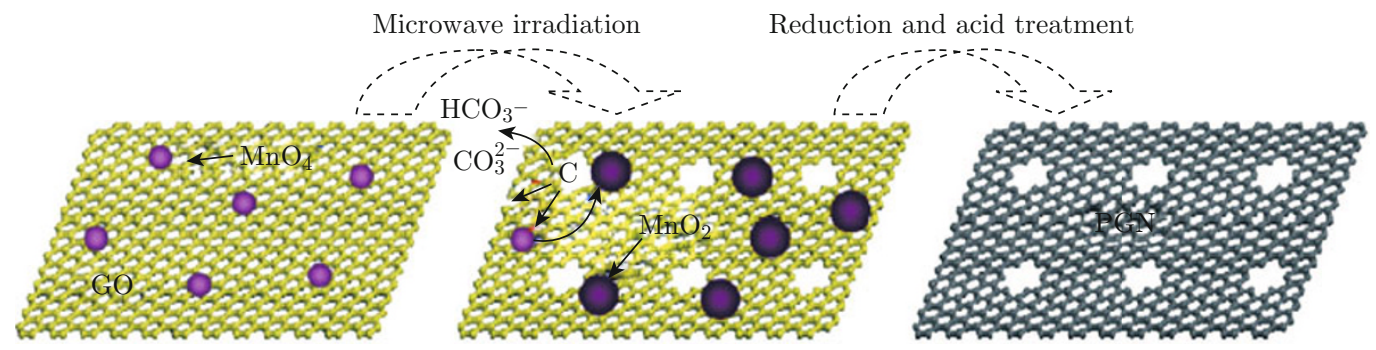

Fig. 5 Scheme for the formation of PG. Adapted from Ref. [61].

(a) $0 \mathrm{~h}$

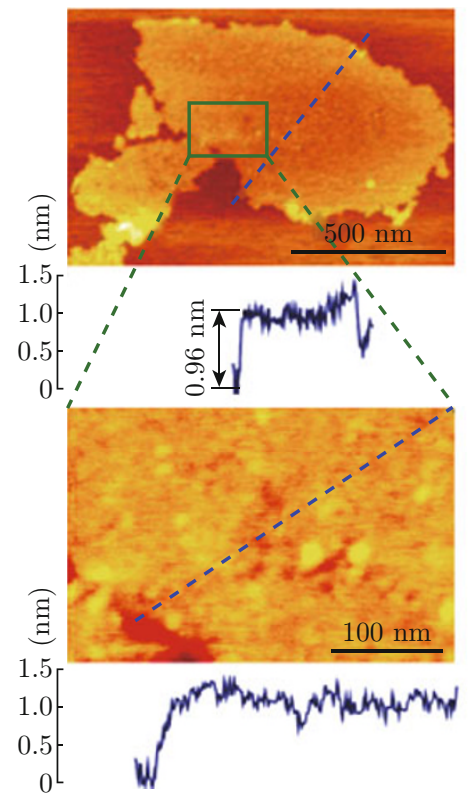

(b) $1 \mathrm{~h}$

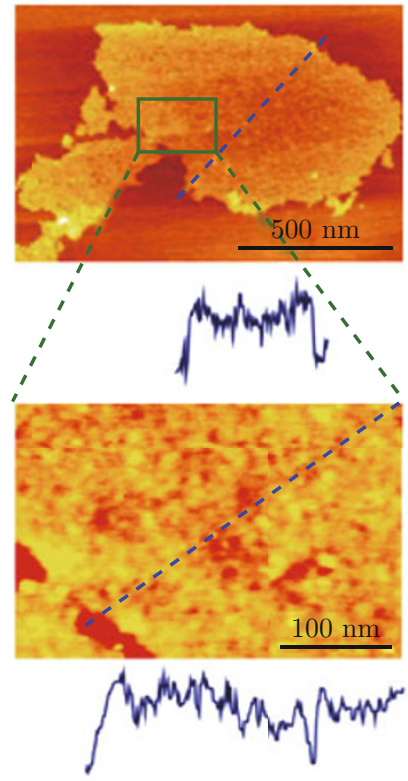

(c) $3 \mathrm{~h}$

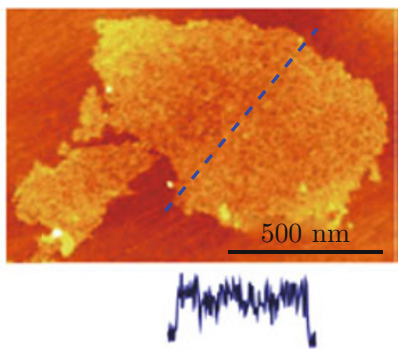

(d) $6 \mathrm{~h}$

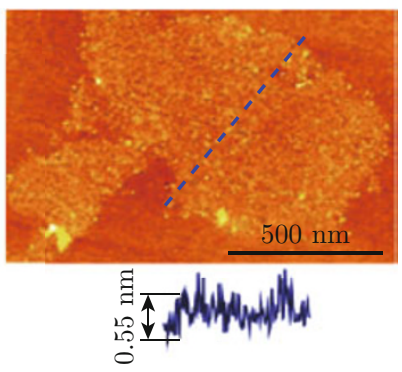

Fig. 6 AFM images of graphene oxide after UV irradiation in $\mathrm{O}_{2}$ at different irradiation times. Adapted from Ref. [63].

According to this equation, the carbon atoms serve as a sacrificial reductant and convert the aqueous permanganate $\left(\mathrm{MnO}_{4}\right)^{-}$to insoluble $\mathrm{MnO}_{2}$, which remain on the surface of the sheet. After $\mathrm{MnO}_{2}$ removal, the resulting sheets possess a wrinkled structure and numerous mesopores, with the sizes of about $2.4 \mathrm{~nm}$.

\section{Photoreaction of graphene oxide in $\mathrm{O}_{2}$ under UV irradiation}

Koinuma et al. [63] reported a simple approach for the production of nanopores in graphene oxide (GO) via photoreaction in $\mathrm{O}_{2}$ under UV irradiation. In this experiment, a solution of graphene oxide was prepared using the Hummers method [62]. The obtained solution was then diluted with pure water, placed on mica and dried under a vacuum. Afterward, a mercury lamp in $\mathrm{O}_{2}$ was employed for the irradiation of the samples. AFM and X-ray photoelectron spectroscopy were used for the characterization of the samples. The AFM images of the samples obtained are displayed in Fig. 6 . It was found that nanopores together with reduced graphene oxide (rGO) and $\mathrm{CO}_{2}$ were produced after
$1 \mathrm{~h}$ of irradiation in $\mathrm{O}_{2}$. In particular, the graphene oxide consists not only of $\mathrm{sp}^{2}$ carbon atoms, but also of oxygenated $\mathrm{sp}^{3}$ carbon bonding domains, which are oxidized by UV irradiation in $\mathrm{O}_{2}$. This evidence can be explained by a mechanism similar to the coal gasification. In particular the $\mathrm{GO}$ contains $\mathrm{C}=\mathrm{C}, \mathrm{C}-\mathrm{C}, \mathrm{CH}$, epoxide (COC), hydroxide $(\mathrm{COH})$, carbonyl $(\mathrm{C}=\mathrm{O})$, and carboxide $(\mathrm{COOH})$ groups, and the authors reported that the oxygen content decreased from 34 to 24 at \% after the photoreaction in $\mathrm{O}_{2}$. The reactions that take place are written below:

$$
\begin{aligned}
& 2 \mathrm{C}=\mathrm{O}+\mathrm{H}_{2} \mathrm{O}(\mathrm{ad}) \rightarrow \mathrm{COH}+\mathrm{COOH}\left(\text { in }_{2}\right) \\
& \mathrm{C}=\mathrm{O}+\mathrm{COOH} \rightarrow \mathrm{CO}_{2}+\mathrm{COH}\left(\text { in } \mathrm{O}_{2}\right) \\
& \mathrm{COC}+\mathrm{H}_{2} \mathrm{O}(\mathrm{ad}) \rightarrow 2 \mathrm{COH}\left(\text { in }_{2}\right) \\
& 4 \mathrm{COH}+\mathrm{O}_{2} \rightarrow 4 \mathrm{C}=\mathrm{O}+2 \mathrm{H}_{2} \mathrm{O}\left(\text { in }_{2}\right)
\end{aligned}
$$

According to the authors the reaction 1 is the trigger reaction for the production of nanopores. In particular, some of the $\mathrm{COOH}$ groups could react with $\mathrm{C}=\mathrm{O}$ to evolve $\mathrm{CO}_{2}$ (reaction 2), which may produce very small size nanopores. In $\mathrm{O}_{2}$, many $\mathrm{C}=\mathrm{O}$ will be produced by 
reaction 4 , leading to promote the reaction 2 increasing the sizes and/or number of the nanopores. The water generated by reaction 4 will promote the production of $\mathrm{COOH}$ (reaction 1 ) and $\mathrm{COH}$ (reactions 1 and 3 ) in $\mathrm{O}_{2}$.

This mechanism was confirmed by the experiments performed employing graphene sheets instead of graphene oxide. The graphene sheets contain only $\mathrm{sp}^{2}$ $\pi$-conjugated domains, and it was found that after their UV irradiation in $\mathrm{O}_{2}$, no pores were formed, confirming that that $\mathrm{O}_{2}$ selectively oxidizes the $\mathrm{sp}^{3}$ oxygenated groups of GO to produce the nanopores.

\section{Coal gasification of graphene oxide sheets by femtosecond laser irradiation}

Recently, we have developed a novel method for the production of porous graphene [64]. In our method, a femtosecond laser is employed for the exfoliation of graphite [64-66] in water, which led to the formation of graphene sheets. The graphene sheets are then oxidized to graphene oxide (GO) layers by $\mathrm{O}_{2}$ and $\mathrm{H}_{2} \mathrm{O}_{2}$ produced by the laser-induced water breakdown. The resulting $\mathrm{sp}^{3}$ carbon atoms of the GO layers reacted simultaneously with $\mathrm{O}_{2}$ in a way similar to that occurring in the coal gasification process. Precisely, coal gasification is a process that occurs when solid carbon-based materials react with oxygen, steam, carbon dioxide, and hydrogen to produce fuel-rich products, such as hydrogen, carbon monoxide, and methane [67]. According to this process, in our method, the free oxygen reacts with the $\mathrm{sp}^{3}$ carbon atoms of the GO. Therefore, $\mathrm{CO}$ and $\mathrm{CO}_{2}$ molecules are formed, leaving carbon vacancies and creating nanopores within the plane. In Fig. 7, SEM image of the obtained porous graphene is shown. To further control the laser processing parameters it is possible to generate porous graphene with controllable the pore population and pore size. The detailed work is under way.

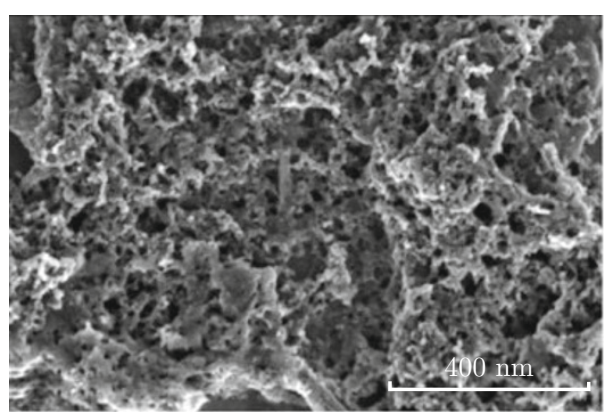

Fig. 7 SEM image of porous graphene by the coal gasification of graphene oxide by femtosecond laser ablation [64].

In addition to the methods described above, there are other ways for the production of porous graphene such as thermolytic cracking of graphene coated polystyrene spheres [68], the coupling of well-designed molecular building blocks on a metal surface [34], and the photoreaction of graphene oxide nanosheets in water [69]. All these methods provide porous graphene sheets with pores of different dimensions and most of them are expensive and time consuming, such as a TEM or SEM apparatus is needed $[59,60]$ or many reactions steps are required as well as the purification of the material [61]. However, the method we developed seems to be a scalable and green approach for the synthesis of porous graphene. It is notable that it is possible to generate monodispersive porous graphene by prohibiting the segregation through adding a proper surfactant $[70,71]$.

\section{Applications of porous graphene}

The increasing interest toward the porous graphene is related to its unique properties and the aim is to obtain large-area of porous graphene for the design of devices for several applications. In this section we will review the potential applications of porous graphene.

\section{Gas separation}

Pure graphene sheets are impermeable to gases due to the high electron density of the aromatic rings that repel any atoms or molecules that try to pass through the graphitic plane. The presence of holes within the graphene plane is necessary to achieve the gas permeability [29], and for this reason, porous graphene has been extensively studied for its use as membrane for gas separation [45-48]. In a theoretical study performed in 2008 by Sint et al. [72], the authors designed functionalized nanopores in graphene sheets and showed that the resulting material could be employed as ionic sieve of high selectivity and transparency. The calculations were done on chemically modified graphene nanopores. The pores were terminated by negatively charged nitrogen and fluorine (F-N-pores), favoring the passage of cations, while the pores terminated by positively charged hydrogen (H-pores), favored the passage of anions. Using molecular dynamics (MD), the authors modeled the passage of different hydrated ions through the nanopores. In the MD simulations, the sheet was placed in a periodic unit cell with $\sim 10 \AA$ of water on each side. One ion was placed in the cell and driven by an electric field $E$ applied in the direction perpendicular to the graphene sheet. From the simulations, it was found that the F-N-pore is only passed by the $\mathrm{Li}^{+}$, $\mathrm{Na}^{+}$, and $\mathrm{K}^{+}$ions, while the H-pore is only passed by the $\mathrm{Cl}^{-}$and $\mathrm{Br}^{-}$ions. This selectivity of the nanopores, even in the presence of a large driving field of $E=0.1$ $\mathrm{Vnm}^{-1}$, is caused by the Coulomb coupling between the ion and the functional groups attached to the nanopore rim. Therefore, the nanopores are also highly selective to the sizes of the ions. Another theoretical study was performed by Jiang and coworkers, in which they computationally demonstrated the possibility of using 
the porous graphene as a membrane for the separation of molecular gases [29]. In particular, by designing subnanometer-sized pores and modeling their selective diffusion of gas molecules with first principles methods, the authors found out the selectivity of the pores for $\mathrm{H}_{2}$ over $\mathrm{CH}_{4}$. These theoretical studies, on porous graphene as membrane for molecular sieving, have been demonstrated in 2012 by Koenig [28]. In this experiment, graphene sheets were prepared by mechanical exfoliation of graphite and deposited on a silicon substrate where an array of circles was previously defined. The pores were then introduced in the graphene sheets, by ultraviolet-induced oxidative etching. The molecular transports of different gases $\left(\mathrm{H}_{2}, \mathrm{CO}_{2}, \mathrm{Ar}, \mathrm{CH}_{4}, \mathrm{~N}_{2}\right.$ and $\mathrm{SF}_{6}$ ) through the pores were measured using a pressurized blister test and mechanical resonance. The measured gas leak rates resulted to be consistent with the theoretical models in the literature based on effusion through ångstrom-sized pores [29,48]. Recently, using molecular dynamics simulations Liu and coworkers [73] showed that porous graphene with pores of $\sim 3.4 \AA$ in size selectively separated $\mathrm{CO}_{2}$ form $\mathrm{N}_{2}$. In particular, the authors tracked the rate of a single-component gas passing through the porous membrane, and by plotting the number of permeate molecules with time for $\mathrm{CO}_{2}$ and $\mathrm{N}_{2}$, the authors noticed that the $\mathrm{CO}_{2}$ molecules permeated through the pores, while the $\mathrm{N}_{2}$ did not pass through [73]. The authors obtained a permeance of 2.8 $\times 10^{5}$ GPU (gas permeation unit) for $\mathrm{CO}_{2}$ and around $2.9 \times 10^{3}$ GPU for $\mathrm{N}_{2}$, yielding a $\mathrm{CO}_{2} / \mathrm{N}_{2}$ selectivity around 100. The same group also investigated the $\mathrm{H}_{2}$ permeance through a porous graphene membrane by classical molecular dynamics simulations [74]. The employed nanoporous graphene had lateral dimensions of the unit cell of $100 \AA \times 100 \AA$ and nanopore density around one per $2500 \AA^{2}$. The authors noticed that the $\mathrm{H}_{2}$ permeated through the nanopores at different pressures and that the passing-through rate increased with the pressure driving force. These theoretical results are consistent with the experimental investigation of Koenig [28]. Liu et al. reported a permeance of $\mathrm{H}_{2}$ of 1 $\times 10^{5}-4 \times 10^{5}$ GPU. The pressure-normalized $\mathrm{H}_{2}$ leak rate at $2 \mathrm{~atm}$ was $5.4 \times 10^{-21} \mathrm{mols}^{-1} \mathrm{~Pa}^{-1}$ while the one reported by Koenig [28] was $4.5 \times 10^{-23} \mathrm{mols}^{-1} \mathrm{~Pa}^{-1}$. This difference, the authors claimed, might be due to the different pore density. The authors suggested that the pore density reported by Koenig was two orders of magnitude smaller than that reported by Liu [74]. Recently, Kim and co-workers experimentally investigated the gas permeation behavior of graphene oxide (GO) membranes [75]. The authors reported that GO films in the dry state were not permeable, however depending on the preparation method, on the presence of water intercalated in the GO layers, and on the nouniform stacking of the layers, GO membranes contained pores and channels, which allowed ingress of gas molecules.
The authors noticed that, when sufficient transmembrane pressure was applied in order to overcome the energy barrier for pore entry and diffusion, the gases can pass through thick GO membranes and that a changing in the GO sheets size could tune the gas permeability [75]. The authors also reported that, when wellinterlocked GO membranes were tested employing feed streams with varying humidity levels; a high $\mathrm{CO}_{2} / \mathrm{N}_{2}$ selectivity was achieved. This evidence made these GO membranes suitable for post-combustion $\mathrm{CO}_{2}$ separation processes. In 2013, Li et al. [76], performed permeation tests employing ultrathin GO membranes deposited on anodic aluminum oxide (AAO). The authors tested the permeation of different small gases through an $18 \mathrm{~nm}$-thick GO membrane and they reported that $\mathrm{H}_{2}$ permeated $\sim 300$ times faster than $\mathrm{CO}_{2}$. Moreover, $\mathrm{Li}$ noticed that the $\mathrm{H}_{2}$ and He permeances decreased exponentially as membrane thickness increased from 1.8 to $20 \mathrm{~nm}$. This exponential dependence of gas permeances on membranes thickness, the authors stated, may be due to the particular molecular transport pathway through the selective structural defects in the GO membranes. The authors found that their ultrathin GO membranes showed superior molecular-sieving performance of $\mathrm{H}_{2}$ over other gases molecules compared with current membranes. This observation showed that these ultrathin GO membranes were promising materials in pre-combustion $\mathrm{CO}_{2}$ capture and $\mathrm{H}_{2}$ recovery for ammonia production [76].

\section{Energy storage}

\section{Lithium-ion batteries}

The lithium-ion batteries (LIB) for their low weight and high-energy storage capacity have attracted special attentions in the scientific and industrial fields as power sources for mobile communication devices, portable electronic devices, and electric vehicles [77]. A lithium-ion battery is typically made up of a lithium intercalation anode and cathode and an electrolyte. The energy density and performance of lithium-ion batteries largely depend on the physical and chemical properties of the electrodes materials. The current electrode materials are carbon black, silicon, metal, metaloxides, and graphite. Among them, graphite electrode is the widely commercial anode material for lithium-ion batteries because of its high columbic efficiency [77]. However, due to the capacity limit of graphite, $372 \mathrm{mAhg}^{-1}$ [78], the energy density of lithium-ion battery cannot satisfy the increasing requirements of portable electronic devices. For this reason, in recent years, many efforts have been carried out towards the development of new electrode materials for next generation lithium-ion batteries [7882]. In particular, graphene-based materials could be one of the promising alternatives as an anode in LIB. It 
was found that employing graphene nanosheets (GNS) as anode materials in LIB, the capacity increased up to $540 \mathrm{mAhg}^{-1}$, and it reached $730 \mathrm{mAhg}^{-1}$ and 784 $\mathrm{mAhg}^{-1}$, respectively, by the incorporation of macromolecules of carbon naotubes and fullerenes to the GNS [83]. In 2007, Takamura and his group [84] found out a higher performance of graphitized materials as anodes for Li charge/discharge, when a number of nano-sized holes were present in the graphene layers. Although there are lots of studies in this field it is still in the early stage. The further enhancement of capacities is possible by optimizing the structures of porous electrodes. Recently, hierarchically porous graphene has been proposed as electrode material for lithium-air (Li-air) battery [49]. The lithium-air batteries are usually defined as batteries consist of Li-based anode and air-cathode which constantly extract oxygen from the ambient air. Porous carbon is usually employed as cathode material with metal catalyst particles, which enhance the oxygen reduction kinetics and increase the specific capacity of the cathode. In this type of battery, Lithium in the anode undergoes a redox reaction; it is oxidized forming lithium ions $\left(\mathrm{Li}^{+}\right)$and electrons. The Lithium ions are constantly transported through the electrolyte to the cathode and react with oxygen molecules. Lithium oxide $\left(\mathrm{Li}_{2} \mathrm{O}\right)$ and lithium peroxide $\left(\mathrm{Li}_{2} \mathrm{O}_{2}\right)$ are generated in the air cathode. This type of battery is one of the most promising technologies, with a theoretical energy density 10 times that of LIB. However, some limitations in Li-air battery development are the relative humidity [85], oxygen partial pressure [86], choice of catalysts [87] and many others [49]. Moreover, the precipitation of reaction products (such as $\mathrm{Li}_{2} \mathrm{O}_{2}$ ) on the carbonaceous electrode limits the capacity of the Liair batteries since the oxygen pathway results blocked. For this reason, an air electrode with microporous and nanoporosity channels could be useful for facilitating rapid oxygen diffusion and can provide reactive sites for $\mathrm{Li}-\mathrm{O}_{2}$ reactions, respectively [49]. Xiao and coworkers in their work demonstrated the construction of hierarchically porous air electrodes with functionalized graphene sheets (FGSs) that contain lattice defects.

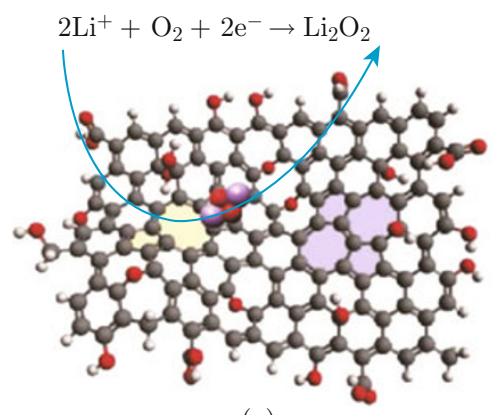

(a)
Figure 8 shows the structure of functionalized graphene model proposed by Xiao for Li- $\mathrm{O}_{2}$ battery operation. The three-dimensional (3D) air electrodes developed in this work showed high capacities, which have been correlated with their pore structures. Density functional theory (DFT) calculations suggested that lattice defect sites on the functionalized graphene play a critical role in the formation of small, nanometer-sized discharge products $\left(\mathrm{Li}_{2} \mathrm{O}_{2}\right)$. The authors demonstrated that, the combination of the hierarchical pore structure and the effect of the defects during the discharge process produced a high capacity of $15000 \mathrm{mAhg}^{-1}$, which is the highest value ever reported in the Li-air battery field [88].

\section{Supercapacitors}

In the last years, the electrochemical supercapacitors have been regarded as promising power devices for the energy storage due to their high power densities, long cycle life, and low maintenance cost $[89,90]$. Thus, supercapacitors could be employed in various applications such as portable electronics and electrical vehicles [50]. Generally, based on the design of the electrodes and on the different energy storage mechanism involved, there are two types of supercapacitors: the electrical doublelayer capacitors (ECDL) based on ion adsorption and the pseudo-capacitors in which the energy is stored through redox reactions [91,92]. The materials studied so far for supercapacitors are carbon [93], activated carbon [94,95], metal oxides [96], carbon nanotubes [97,98]. It was widely reported [94,95] that, activated carbon could be employed as electrodes in double-layer capacitors, therefore, the capacitance property depends not only on electrolyte but also on the material in terms of pore size distribution, conductivity and so on. In particular, Qu [95] demonstrated that activated carbons with larger percentage of bigger pores are more suitable to high-power supercapacitor applications because it can deliver high energy at a high discharging rate, although it may store the less total energy [95]. Recently, the attention of some researchers moved towards the

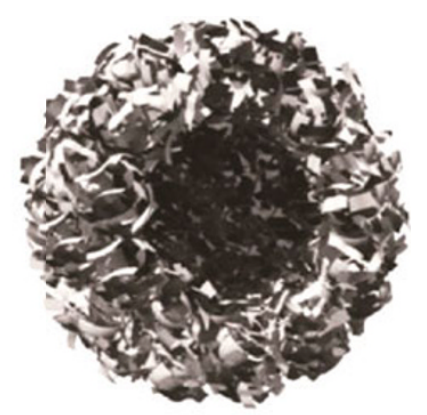

(b)

Fig. 8 Schematic structure of a functionalized graphene sheet (a) with an ideal bimodal porous structure; (b) required for Li- $\mathrm{O}_{2}$ battery operation. Adapted from Ref. [49]. 
use of graphene and graphene-based materials for the realization of supercapacitors [99-104], due to the large specific area of $2630 \mathrm{~m}^{2} \mathrm{~g}^{-1}$ [99] and high electrical conductivity [2] showed by graphene. In particular, some studies have been done on the use of porous graphene for the realization of supercapacitors $[44,50,105]$. Fan et al. [61] demonstrated that the porous graphene nanosheets (PGNs) synthesized by the etching of graphene sheets by $\mathrm{MnO}_{2}$, can be used as electrode in supercapacitors. In this work, the authors found that the PGNs, exhibited a specific capacitance of $154 \mathrm{Fg}^{-1}$ at $500 \mathrm{mVs}^{-1}$ compared to a value of $67 \mathrm{Fg}^{-1}$ for pure graphene nanosheets. They also found a decrease of the capacitance of $12 \%$ of the initial capacitance after 5000 cycles, demonstrating a good electrochemical stability of PGNs electrodes [61]. Moreover, compared to the active carbon electrodes, PGNs have better capacitive performances at high rates due to their mesopores structure (pore size 2-50 nm) [102], that eases the access of electrolytes to electrode material leading to a shorter ion diffusion pathway through the pores [61]. In addition, Zhang and his group demonstrated the use of a porous activated reduced graphene oxide as electrode in supercapacitors [105]. In that work, the porous carbon thin films prepared by simple $\mathrm{KOH}$ activation of reduced graphene oxide film, showed a very high specific surface area of $2400 \mathrm{~m}^{2} \mathrm{~g}^{-1}$. A supercapacitor constructed employing these films as electrodes demonstrated the outstanding power density $\left(\sim 500 \mathrm{kWkg}^{-1}\right)$ and high-frequency performance. These works highlight the advantages and improvements, in the field of energy storage, made by the use of porous graphene sheets as electrodes, encouraging more investigations on this promising material.

\section{Nanoelectronics}

Pure graphene, as aforementioned, is a zero-gap semiconductor [15] and it cannot be employed for field-effect transistors [2], and many efforts have been done in order to open a band gap. However, cutting graphene sheets into nanoribbons and creating some holes in the graphene plane can open a band gap, leading to the use of these modified sheets for the fabrication of transistors [106]. Porous graphene, due to the presence of holes in the plane, has a band gap that vary from 2.3 up to $3.95 \mathrm{eV}$ depending on the computational methods employed [56-58]. For such reason, porous graphene has been considered as a promising material for the fabrication of field-effect transistors, as demonstrated by Bai and coworkers [33]. In particular, the authors produced "graphene nanomeshes", which are single-and few-layers graphene sheets into which a high density of nanoscale holes have been created using block copolymer lithography. Moreover, controlling the etching during the fabrication process, the authors stated it was possible to control both the neck widths and the periodicities of the holes. To test the electronic properties of the prepared graphene nanomeshes (GNMs), Bai fabricated a graphene nanomesh-transistor (GNM-FET) and performed electrical transport studies. A scheme of the GNW-FET is reported in Fig. 9. A three-terminal device was made using the GNM as the semiconducting channel, electron-beam evaporated titanium/gold pads as the source-drain contacts, a highly doped p-type silicon substrate as the back gate, and a 300-nm thermal oxide as the gate dielectric. Employing this system, Bai and coworkers, demonstrated that the GNM-FET can supports currents nearly 100 times greater than that of an individual graphene nanoribbon device, but with a comparable on-off ratio that is tunable by varying the neck width.

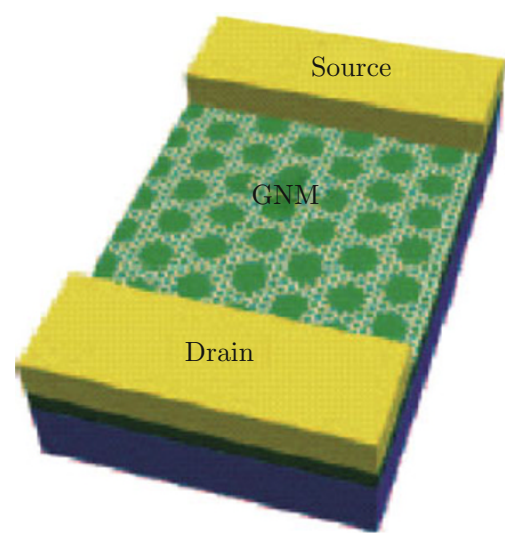

Fig. 9 Scheme of GNM-FET [33].

\section{Conclusions and Outlook}

In summary, we have showed different preparation methods of porous graphene and we focused on the potential applications of this promising material. Porous graphene is a graphene sheet in which some carbon atoms are missing. Due to this unique structure, porous graphene shows properties different from those of graphene, and for this reason, it has been proposed as a suitable material for gas purification and energy storage. In the last years, many physical and chemical synthetic approaches have been proposed. Some of them, such as the physical method proposed by Fischbein [59], permit a control on the pores size but it is very expensive. The chemical approaches, consisting of many reactions steps are time consuming, therefore a cheaper method that permits large-scale production of porous graphene is highly desirable. The approach we developed, the coal gasification of graphene oxide employing a femtosecond laser exfoliation of graphite, seems to be scalable and cheaper way to obtain the porous graphene, even if a way for the control of the pore sizes is needed. 
More experimental investigations are necessary in order to improve the performances of the existing devices and to explore more applications of porous graphene. For instance, recently it was reported that graphene and graphene oxide could be promising candidates for developing high performance photocatalysts. In particular, composites of either graphene and $\mathrm{TiO}_{2}$ nanoparticles or graphene oxide and $\mathrm{TiO}_{2}$ nanoparticles [107-110] are currently being considered as potential photocatalysts in air and water purification. For its particular properties and for its higher amount of accessible surface area, porous graphene could be a promising candidate as material for the development of new $\mathrm{TiO}_{2}$ porous graphene nanocomposites. A first study has been conducted by Stengl [111], where they synthesized mesoporous $\mathrm{TiO}_{2}$-graphene oxide nanocomposites with a specific surface area of almost $\sim 80-200 \mathrm{~m}^{2} \mathrm{~g}^{-1}$, larger than those of $\mathrm{TiO}_{2}$ nanoparticles (P25) [108]. The authors reported a better photocatalytic degradation of butane in the gas phase attributed different effects including the increase in specific surface area. By developing suitable nano-manipulation and nano-assembling techniques [112] porous graphene is a very attractive materials for a range of applications.

\section{Acknowledgements}

The work is partially supported by the Natural Science and Engineering Council of Canada (NSERC, Canada). One of authors (A. Hu) would like thank the financial support from the high level overseas talent project of Beijing, P. R. China.

\section{References}

[1] A. K. Geim and K. S. Novoselov, "The rise of graphene", Nat. Mater. 6, 183-191 (2007). http:// dx.doi.org/10.1038/nmat1849

[2] K. S. Novoselov, A. K. Geim, S. V. Morozov, D. Jiang, Y. Zhang, S. V. Dubonos, I. V. Grigorieva and A. A. Firsov "Electric field effect in atomically thin carbon films", Science 306, 666-669 (2004). http:// dx.doi.org/10.1126/science. 1102896

[3] T. Ohta, A. Bostwick, T. Seyller, K. Horn and E. Rotenberg, "Controlling the electronic structure of bilayer graphene", Science 313, 951-954 (2006). http://dx.doi.org/10.1126/science.1130681

[4] L. Kane and E. J. Mele, "Quantum spin hall effect in graphene", Phys. Rev. Lett. 95(22), 226801-4 (2005). http://dx.doi.org/10.1103/PhysRevLett. 95. 226801

[5] M. A. H. Vozmediano, M. P. Lopez-Sancho, T. Stauber and F. Giunea, "Local defects and ferromagnetism in graphene layers", Phys. Rev. B 72(15), 155121-5 (2005). http://dx.doi.org/10. 1103/PhysRevB. 72.155121
[6] A. Reina, X. Jia, J. Ho, D. Nezich, H. Son, V. Bulovic, M. S. Dresselhaus and J. Kong, "Large area, fewlayer graphene films on arbitrary substrates by chemical vapor deposition", Nano Lett. 9(1), 30-35 (2009). http://dx.doi.org/10.1021/nl801827v

[7] X. Li, W. Cai, J. An, S. Kim, J. Nah, D. Yang, R. Piner, A. Velamakanni, I. Jung, E. Tutuc, S. K. Banerjee, L. Colombo and R. S. Ruoff, "Large-area synthesis of high-quality and uniform graphene films on copper foils", Science 324(5932), 1312-1314 (2009). http://dx.doi.org/10.1126/science. 1171245

[8] K. S. Kim, Y. Zhao, H. Jang, S. Y. Lee, J. M. Kim, K. S. Kim, J.-H. Ahn, P. Kim, J.-Y. Choi and B. Hee Hong, "Large-scale pattern growth of graphene films for stretchable transparent electrodes", Nature 457, 706-710 (2009). http://dx.doi.org/10.1038/ nature07719

[9] Y. Hernandez, V. Nicolosi, M. Lotya, F. M. Blighe, Z. Sun, S. De, I. T. McGovern, B. Holland, M. Byrne, Y. K. Gun'Ko, J. J. Boland, P. Niraj, G. Duesberg, S. Krishnamurthy, R. Goodhue, J. Hutchison, V. Scardaci, A. C. Ferrari and J. N. Coleman, "High-yield production of graphene by liquid-phase exfoliation of graphite", Nat. Nanotech. 3, 563-568 (2008). http:// dx.doi.org/10.1038/nnano.2008.215

[10] H. C. Schniepp, J. L. Li, M. J. McAllister, H. Sai, M. Herrera-Alonso, D. H. Adamson, R. K. Prud'homme, R. Car, D. A. Saville and I. A. J. Aksay, "Functionalized single graphene sheets derived from splitting graphite oxide", J. Phys. Chem. B 110(17), 8535-8539 (2006). http://dx.doi.org/10.1021/jp060936f

[11] S. Niyogi, E. Bekyarova, M. E. Itikis, J. L. McWilliams, M. A. Hammon and R. C. Haddon, "Solution properties of graphite and graphene", J. Am. Chem. Soc. 128(24), 7720-7721 (2006). http://dx. doi.org/10.1021/ja060680r

[12] M. Zhou, Y. M. Zhai and S. J. Dong, "Electrochemical sensing and biosensing platform based on chemically reduced graphene oxide", Anal. Chem. 81(14), 5603-5613 (2009). http://dx.doi.org/10. $1021 /$ ac900136z

[13] H. Bi, S. Sun, F. Huang, X. Xieb and M. Jiang, "Direct growth of few-layer graphene films on $\mathrm{SiO}_{2}$ substrates and their photovoltaic applications", J. Mater. Chem. 22, 411-416 (2012). http://dx.doi.org/10. 1039/c1jm14778a

[14] W. Choi and J-W. Lee, "Graphene: Synthesis and Applications", CRC Press, Taylor \& Francis group, 2012. ISBN: 978-1-4398-6187-5.

[15] K. S. Novoselov, A. K. Geim, S. V. Morozov, D. Jiang, M. I. Katsnelson, I. V. Grigorieva, S. V. Dubonos and A. A. Firsov, "Two-dimensional gas of massless dirac fermions in graphene", Nature 438, 197-200 (2005). http://dx.doi.org/10.1038/ nature 04233

[16] X. Wang, X. Li, L. Zhang, Y. Yoon, P. K. Weber, H. Wang, J. Guo and H. Dai, "N-doping of graphene through electrothermal reactions with ammonia", Science 324(5928), 768-771 (2009). http:// dx.doi.org/10.1126/science. 1170335 
[17] Y. Shao, S. Zhang, M. H. Engelhard, G. Li, G. Shao, Y. Wang, J. Liu, I. A. Aksay and Y. Lin, "Nitrogen-doped graphene and its electrochemical applications", J. Mater. Chem. 20, 7491-7496 (2010). http://dx.doi.org/10.1039/c0jm00782j

[18] X. Wang, L. Zhi, and K. Müllen, "Transparent, conductive graphene electrodes for dye-sensitized solar cells", Nano Lett. 8(1), 323-327 (2008). http://dx. doi.org/10.1021/nl072838r

[19] D. Kim, D. Lee, Y. Lee and D. Y. Jeon, "Workfunction engineering of graphene anode by bis (trifluoromethanesulfonyl) amide doping for efficient polymer light-emitting diodes", Adv. Funct. Mater. 23(40), 5049-5055 (2013). http://dx.doi.org/10. 1002/adfm201301386

[20] J. Ha, S. Park, D. Kim, J. Ryu, C. Lee, B. H. Hong and Y. Hong, "High-performance polymer light emitting diodes with interface-engineered graphene anodes", Organic Electronics 14(9), 2324-2330 (2013). http://dx.doi.org/10.1016/j.orgel.2013.05.033

[21] X. Michalet, F. F. Pinaud, L. A. Bentolila, J. M. Tsay, S. Doose, J. J. Li, G. Sundaresan, A. M. Wu, S. S. Gambhir and S. Weiss, "Quantum dots for live cells, in vivo imaging, and diagnostics", Science 307(5709), 538-544 (2005). http://dx.doi.org/10. 1126/science. 1104274

[22] B. D. Zdravkov, J. J. Cermak, M. Sefara and J. Jank, "Pore classification in the characterization of porous materials: a perspective", Cent. Eur. J. Chem. 5(2), 385-395 (2007). http://dx.doi.org/10.2478/ s11532-007-0017-9

[23] C. Liang, Z. Li and S. Dai, "Mesoporous carbon materials: synthesis and modification", Angew Chem. Int. Ed. 47, 3696-3717 (2008). http://dx.doi.org/ 10. 1002/anie. 200702046

[24] T. Kyotani, "Control of pore structure in carbon", Carbon 38(2), 269-286 (2000). http://dx.doi.org/ 10.1016/S0008-6223(99) 00142-6

[25] C. R. Bansal, J. B. Donnet and F. Stoeckl, "Active carbon", Marcel Dekker, New York, pp.482 (1988).

[26] J. S. Bunch, S. S Verbridge, J. S. Alden, A. M. van der Zande, J. M. Parpia, H. G. Craighead and P. L. McEuen, "Impermeable atomic membranes from graphene sheets", Nano Lett. 8(8), 2458-2462, (2008). http://dx.doi.org/10.1021/nl801457b

[27] S. Patchkovskii, J. S. Tse, S. N. Yurchenko, L. Zhechkov, T. Heine and G. Seifert, "Graphene nanostructures as tunable storage media for molecular hydrogen", Proc. Natl. Acad. Sci. 102, 1043910444 (2005). http://dx.doi.org/10.1073/pnas. 0501030102

[28] S. P. Koenig, L. Wang, J. Pellegrino and J. S. Bunch, "Selective molecular sieving through porous graphene", Nat. Nanotech. 7, 728-732, (2012). http://dx.doi.org/10.1038/nnano.2012.162

[29] D. Jiang, V. R. Cooper and S. Dai, "Porous graphene as the ultimate membrane for gas separation", Nano Lett. 9(12), 4019-4024 (2009). http://dx.doi.org/ $10.1021 /$ n19021946
[30] J. Zhu, D. Yang, X. Rui, D. Sim, H. Yu, H. E. Hoster, P. M. Ajayan and Q. Yan, "Facile preparation of ordered porous graphene-metal oxide@C binderfree electrodes with high Li storage performance", Small 9(20), 3390-3397 (2013). http://dx.doi.org/ 10.1002/smll.201300755

[31] Y. Yan, Y. X. Yin, S. Xin, Y. G. Guo and L. J. Wan, "Ionothermal synthesis of sulfur-doped porous carbons hybridized with graphene as superior anode materials for lithium-ion batteries", Chem. Commun. 48, 10663-10665 (2012). http://dx.doi.org/ 10.1039/c2cc36234a

[32] A. Du, Z. Zhu and S. C. Smith, "Multifunctional porous graphene for nanoelectronics and hydrogen storage: new properties revealed by first principle calculations", J. Am. Chem. Soc. 132(9), 2876-2877 (2010). http://dx.doi.org/10.1021/ja100156d

[33] J. Bai, X. Zhong, S. Jiang, Y. Huang and X. Duan, "Graphene nanomesh", Nat. Nanotech. 5, 190-194 (2010). http://dx.doi.org/10.1038/nnano.2010.8

[34] M. Bieri, M. Treier, J. Cai, K. Ait-Mansour, P. Ruffieux, O. Groning, P. Groning, M. Kastler, R. Rieger, X. Feng, K. Mullen and R. Fasel, "Porous graphenes: two-dimensional polymer synthesis with atomic precision", Chem. Commun. 45, 6919-6921 (2009). http://dx.doi.org/10.1039/b915190g

[35] Y. Li, Z. Zhou, P. Shena and Z. Chen, "Twodimensional polyphenylene: experimentally available porous graphene as a hydrogen purification membrane", Chem. Commun. 46, 3672-3674 (2010). http://dx.doi.org/10.1039/b926313f

[36] W. Frank, D. M. Tanenbaum, A. M. Van der Zande and P. L. McEuen, "Mechanical properties of suspended graphene sheets", J. Vac. Sci. Technol. B 25, 2558-2561 (2007). http://dx.doi.org/10.1116/ 1. 2789446

[37] C. Lee, X. Wei, J.W. Kysar and J. Hone, "Measurement of the elastic properties and intrinsic strength of monolayer graphene", Science 321, 385-388 (2008). http://dx.doi.org/10.1126/science. 1157996

[38] A. A. Balandin, S. Ghosh, W. Bao, I. Calizo, D. Teweldebrhan, F. Miao and C. N. Lau, "Superior thermal conductivity of single-layer graphene", Nano Lett. 8(3), 902-907 (2008). http://dx.doi.org/10. $1021 / \mathrm{nl} 0731872$

[39] C. Faugeras, B. Faugeras, M. Orlita, M. Potemski, R. R. Nair and A. K. Geim, "Thermal conductivity of graphene in corbino membrane geometry", ACS Nano 4(4), 1889-1892 (2010). http://dx.doi.org/ 10.1021/nn9016229

[40] W. Cai, A. L. Moore, Y. Zhu, X. Li, S. Chen, L. Shi and R. S. Ruoff, "Thermal transport in suspended and supported monolayer graphene grown by chemical", Nano Lett. 10(5), 1645-1651 (2010). http://dx. doi.org/10.1021/nl9041966

[41] H. W. Ha, A. Choudhury, T. Kamal, D.-H. Kim and S.-Y. Park, "Effect of chemical modification of graphene on mechanical, electrical, and thermal properties of polyimide/graphene nanocomposites", 
ACS Appl. Mater. Interfaces 4(9), 4623-4630, (2012). http://dx.doi.org/10.1021/am300999g

[42] M. Mecklenburg, A. Schuchardt, Y. K. Mishra, S. Kaps, R. Adelung, A. Lotnyk, L. Kienle and K. Schulte, "Aerographite: ultra lightweight, flexible nanowall, carbon microtube material with outstanding mechanical performance", Adv. Mater. 24(26), 3486-3490 (2012). http://dx.doi.org/10. 1002/adma. 201290158

[43] S. Murali, J. R. Potts, S. Stoller, J. Park, M. D. Stoller, L. L. Zhang, Y. Zhu and R. S. Ruoff, "Preparation of activated graphene and effect of activation parameters on electrochemical capacitance", Carbon 50, 3482-3485 (2012). http://dx.doi.org/10.1016/ j. carbon. 2012.03.014

[44] L. Zhang, F. Zhang, X. Yang, G. Long, Y. Wu, T. Zhang, K. Leng, Y. Huang, Y. Ma, A. Yu and Y. Chen, "Porous 3D graphene-based bulk materials with exceptional high surface area and excellent conductivity for supercapacitors", Scientific Reports 3, 1408-1417 (2013). http://dx.doi.org/10.1038/ srep01408

[45] H. Du, J. Li, J. Zhang, G. Su, X. Li and Y. Zhao, "Separation of hydrogen and nitrogen gases with porous graphene membrane", J. Phys. Chem. C 115(47), 23261-23266 (2011). http://dx.doi.org/ 10.1021/jp206258u

[46] J. Schrier, "Helium separation using porous graphene membranes", J. Phys. Chem. Lett. 1(15), 2284-2287 (2010). http://dx.doi.org/10.1021/jz100748x

[47] W. Hauser and P. Schwerdtfeger, "Nanoporous graphene membranes for efficient ${ }^{3} \mathrm{He} /{ }^{4} \mathrm{He}$ separation", J. Phys. Chem. Lett. 3(2), 209-213 (2012). http://dx.doi.org/10.1021/jz201504k

[48] S. Blankenburg, M. Bieri, R. Fasel, K. Mullen, C. A. Pignedoli and D. Passerone, "Porous graphene as an atmospheric nanofilter", Small 6(20), 2266-2271 (2010). http://dx.doi.org/10. $1002 / \mathrm{smll} .201090068$

[49] J. Xiao, D. Mei, X. Li, W. Xu, D. Wang, G. L. Graff, W. D. Bennett, Z. Nie, L. V. Saraf, I. A. Aksay, J. Liu and J.-G. Zhang, "Hierarchically porous graphene as a Lithium-air battery electrode", Nano Lett. 11(11), 5071-5078 (2011). http://dx.doi.org/ 10.1021/nl203332e

[50] J. Yan, Z. Fan, W. Sun, G. Ning, T. Wei, Q. Zhang, R. Zhang, L. Zhi and F. Wei, "Advanced asymmetric supercapacitors based on $\mathrm{Ni}(\mathrm{OH})_{2}$ /graphene and porous graphene electrodes with high energy density", Adv. Funct. Mater. 22(12), 2632-2641 (2012). http://dx.doi.org/10.1002/adfm. 201102839

[51] J. Zhao, W. Ren and H.-M.Cheng, "Graphene sponge for efficient and repeatable adsorption and desorption of water contaminations", J. Mater. Chem. 22, 20197-20202 (2012). http://dx.doi.org/10.1039/ c2jm34128j

[52] H. Bi, X. Xie, K. Yin, Y. Zhou, S. Wan, L. He, F. $\mathrm{Xu}$, F. Banhart, L. Sun and R. S. Ruoff, "Spongy graphene as a highly efficient and recyclable sorbent for oils and organic solvents", Adv. Funct. Mater. 22(21), 4421-4425 (2012). http://dx.doi.org/10. 1002/adfm. 201200888

[53] R. Balog, B. Jørgensen, L. Nilsson, M. Andersen, E. Rienks, M. Bianchi, M. Fanetti, E. Lægsgaard, A. Baraldi, S. Lizzit, Z. Sljivancanin, F. Besenbacher, B. Hammer, T. G. Pedersen, P. Hofmann and L. Hornekær, "Band gap opening in graphene induced by patterned hydrogen adsorption", Nat. Mater. 9, 315-319 (2010). http://dx.doi.org/10. $1038 /$ nmat 2710

[54] F. Cervantes-Sodi, G. Csanyi, S. Piscanec and A. C Ferrari, "Edge functionalized and substitutionally doped graphene nanoribbons: electronic and spin properties", Phys. Rev. B 77(16), 165427-165439 (2008). http://dx.doi.org/10.1103/PhysRevB.77. 165427

[55] M. Vanevic, M. S. Stojanovic and M. Kindermann, "Character of electronic states in graphene antidot lattices: flat bands and spatial localization", Phys. Rev. B 80(4), 045410-045417 (2009). http://dx.doi. org/10.1103/PhysRevB.80.045410

[56] M. De La Pierre, P. Karamanis, J. Baima, R. Orlando, C. Pouchan, and R. Dovesi, "Ab initio periodic simulation of the spectroscopic and optical properties of novel porous graphene phases", J. Phys. Chem. C 117(5), 2222-2229 (2013). http://dx.doi.org/10. 1021/jp3103436

[57] G. Brunetto, P. A. S. Autreto, L. D. Machado, B. I. Santos, R. P. B. dos Santos, D. S. Galvão, "A nonzero gap two-dimensional carbon allotrope from porous graphene", J. Phys. Chem. C 116(23), 12810-12813 (2012). http://dx.doi.org/10.1021/jp211300n

[58] Y. Matsuda, J. Tahir-Kheli and W. A. III Goddard, "Definitive band gaps for single-wall carbon nanotubes", J. Phys. Chem. Lett. 1(19), 2946 (2010). http://dx.doi.org/10.1021/jz100889u

[59] M. D. Fischbein and M. Drndic, "Electron beam nanosculpting of suspended graphene sheets", Appl. Phys. Lett. 93(11), 113107-113109 (2008). http:// dx.doi.org/10.1063/1.2980518

[60] D. Fox, A. O'Neill, D. Zhou, M. Boese, J. N. Coleman and H. Z. Zhang, "Nitrogen assisted etching of grapheme layers in a scanning electron microscope", Appl. Phys. Lett. 98(24), 243117-243119 (2011). http://dx.doi.org/10.1063/1.3601467

[61] Z. Fan, Q. Zhao, T. Li, J. Yan, Y. Ren, J. Feng and T. Wei, "Easy synthesis of porous graphene nanosheets and their use in supercapacitors", Carbon 50, 1699-1712 (2012). http://dx.doi.org/10.1016/ j.carbon. 2011.12 .016

[62] W. S. Hummers and R. E Offeman, "Preparation of graphitic oxide", J. Am. Chem. Soc. 80(6), 1339 (1958). http://dx.doi.org/10.1021/ja01539a017

[63] M. Koinuma, C. Ogata, Y. Kamei, K. Hatakeyama, H. Tateishi, Y. Watanabe, T. Taniguchi, K. Gezuhara, S. Hayami, A. Funatsu, M. Sakata, Y. Kuwahara, S. Kurihara and Y. Matsumoto, "Photochemical engineering of graphene oxide nanosheets", 
J. Phys. Chem. C 116(37), 19822-19827 (2012). http://dx.doi.org/10.1021/jp305403r

[64] P. Russo, A. Hu, G. Compagnini, W. W. Dule and N. Y. Zhou. Submitted to Nanoscale.

[65] H. O. Jeschke, M. E. Garcia and K. H. Bennemann, "Theory for the ultrafast ablation of graphite films", Phys. Rev. Lett. 87(1), 015003-015006 (2001). http://dx.doi.org/10.1103/PhysRevLett. 87.015003

[66] Y. Miyamoto, H. Zhang and D. Tománek, "Photoexfoliation of graphene from graphite: an $\mathrm{Ab}$ initio study", Phys. Rev. Lett. 104(20), 208302-208307 (2010). http://dx.doi.org/10.1103/PhysRevLett. 104.208302

[67] L. D. Smoot and P. J. Smith, "Coal combustion and gasification: gasification of coal in practical flames", Plenum Press: New York, 151-162 (1985).

[68] D. Fan, Y. Liu, J. He, Y. Zhou and Y. Yang, "Porous graphene-based materials by thermolytic cracking", J. Mater. Chem. 22, 1396-1402 (2012). http://dx. doi.org/10.1039/c1jm13947a

[69] Y. Matsumoto, M. Koinuma, S. Ida, S. Hayami, T. Taniguchi, K. Hatakeyama, H. Tateishi, Y. Watanabe and S. Amano, "Photoreaction of graphene oxide nanosheets in water", J. Phys. Chem. C 115(39), 19280-19286 (2011). http://dx.doi.org/10.1021/ jp206348s

[70] M. Lotya, P. J. King, U. Khan, S. De and J. N. Coleman, "High-concentration, surfactant-stabilized graphene dispersions", ACS Nano 4(6), 3155-3162 (2010). http://dx.doi.org/10.1021/nn1005304

[71] J. Shen, Y. Zhu, X. Yang, J. Zong, J. Zhang and C. Li, "One-pot hydrothermal synthesis of graphene quantum dots surface-passivated by polyethylene glycol and their photoelectric conversion under nearinfrared light", New J. Chem. 36, 97-101 (2012). http://dx.doi.org/10.1039/c1nj20658c

[72] K. Sint, B. Wang and P. Kral, "Selective ion passage through functionalized graphene nanopores", J. Am. Chem. Soc. 130(49), 16448-16449 (2008). http://dx. doi.org/10.1021/ja804409f

[73] H. Liu, S. Dai and D. Jiang, "Insights into $\mathrm{CO}_{2} / \mathrm{N}_{2}$ separation through nanoporous graphene from molecular dynamics", Nanoscale 5, 9984-9987 (2013). http://dx.doi.org/10.1039/c3nr02852f

[74] H. Liu, S. Dai and D. Jiang, "Permeance of $\mathrm{H}_{2}$ through porous graphene from molecular dynamics", Solid State Commun. In press (2013). http://dx. doi.org/10.1016/j.ssc.2013.07.004

[75] H. W. Kim, H. W. Yoon, S.-M. Yoon, B. M. Yoo, B. K. Ahn, Y. H. Cho, H. J. Shin, H. Yang, U. Paik, S. Kwon, J.-Y. Choi, H. B. Park, "Selective gas transport through few-layered graphene and graphene oxide membranes", Science 342, 91-95 (2013). http:// dx.doi.org/10.1126/science. 1236098

[76] H. Li, Z. Song, X. Zhang, Y. Huang, S. Li, Y. Mao, H. J. Ploehn, Y. Bao and M. Yu, "Ultrathin, molecular-sieving graphene oxide membranes for selective hydrogen separation", Science 342, 9598 (2013). http://dx.doi.org/10.1126/science. 1236686

[77] S.-M. Paek, E. Yoo and I. Honma, "Enhanced cyclic performance and lithium storage capacity of $\mathrm{SnO}_{2}$ /graphene nanoporous electrodes with threedimensionally delaminated flexible structure", Nano Lett. 9(1), 72-75 (2009). http://dx.doi.org/10. 1126/science. 1236686

[78] M. Liang and L. Zhi, "Graphene-based electrode materials for rechargeable lithium batteries", J. Mater. Chem. 19, 5871-5878 (2009). http://dx.doi.org/ 10.1039/b901551e

[79] M. Tarascon and M. Armand, "Issues and challenges facing rechargeable lithium batteries", Nature 414, 359-367 (2001). http://dx.doi.org/10.1038/ 35104644

[80] Y. Idota, T. Kubota, A. Matsufuji, Y. Maekawa and T. Miyasaka, "Tin-based amorphous oxide: a high-capacity lithium-ion-storage material", Science 276(5317), 1395-1397 (1997). http://dx.doi.org/ 10.1126/science.276.5317.1395

[81] P. Poizot, S. Laruelle, S. Grugeon, L. Dupont and J. M. Tarascon, "Nano-sized transition-metal oxides as negative-electrode-materials for lithium-ion batteries", Nature 407, 496-499 (2000). http://dx.doi. org/10.1038/35035045

[82] G. Wang, B. Wang, X. Wang, J. Park, S. Dou, H. Ahn and K. Kim, "Sn/graphene nanocomposite with 3D architecture for enhanced reversible lithium storage in lithium ion batteries", J. Mater. Chem. 19, 83788384 (2009). http://dx.doi.org/10.1039/b914650d

[83] E. Yoo, J. Kim, E. Hosono, H.-S. Zhou, T. Kudo and I. Honma, "Large reversible Li storage of graphene nanosheet families for use in rechargeable lithium ion batteries", Nano Lett. 8(8), 2277-2282 (2008). http://dx.doi.org/10.1021/n1800957b

[84] T. Takamura, K. Endo, L. Fu, Y. Wu, K. J. Lee and T. Matsumoto, "Identification of nano-sized holes by TEM in the graphene layer of graphite and the high rate discharge capability of Li-ion battery anodes", Electrochim. Acta 53(3), 1055-1061 (2007). http:// dx.doi.org/10.1016/j.electacta. 2007.03.052

[85] G. Zhang, D. Wang, W. Xu, J. Xiao and R. E. Williford, "Ambient operation of Li/air batteries", J. Power Sources 195(3), 4332-4337 (2010). http://dx. doi.org/10.1016/j.jpowsour. 2010.01.022

[86] J. Read, K. Mutolo, M. Ervin, W. Behl, J. Wolfenstine, A. Driedger and D. Foster, "Oxygen transport properties of organic electrolytes and performance of lithium/oxygen battery", J. Electrochem. Soc. 150(10), 1351-1356 (2003). http://dx.doi.org/ 10.1149/1.1606454

[87] A. Débart, A. J. Paterson, J. Bao and P. G. Bruce, " $\alpha-\mathrm{MnO}_{2}$ nanowires: a catalyst for the $\mathrm{O}_{2}$ electrode in rechargeable lithium batteries", Angew. Chem. 120(24), 4597-4600 (2008). http://dx.doi.org/10. 1002/ange. 200705648 
[88] J. Christensen, P. Albertus, R. S. Sanchez-Carrera, T. Lohmann, B. Kozinsky, R. Liedtke, J. Ahmed and A. Kojic, "A critical review of Li/air batteries", J. Electrochem. Soc. 159(2), 1-30 (2012). http://dx. doi.org/10.1149/2.086202jes

[89] P. Simon and Y. Gogotsi, "Materials for electrochemical capacitors", Nat. Mater. 7, 845-854 (2008). http://dx.doi.org/10.1038/nmat2297

[90] A. Burke, "Ultracapacitors: why, how, and where is the technology", J. Power Sources 91(1), 37-50 (2000). http://dx.doi.org/10.1016/ S0378-7753 (00) 00485-7

[91] E. Conway, V. Birss and J. Wojtowicz, "The role and utilization of pseudocapacitance for energy storage by supercapacitors", J. Power Sources 66(1-2), 1-14 (1997). http://dx.doi.org/10.1016/ S0378-7753 (96) 02474-3

[92] H. Wang, Y. Liang, T. Mirfakhari, Z. Chen, H. S. Casalongue and H. Dai, "Advanced asymmetrical supercapacitors based on graphene hybrid materials", Nano Res. 4(8), 729-736 (2011). http://dx.doi.org/ 10.1007/s12274-011-0129-6

[93] E. Frackowiak and F. Béguin, "Carbon materials for the electrochemical storage of energy in capacitors", Carbon 39(6), 937-950 (2001). http://dx.doi.org/ 10. 1016/S0008-6223(00)00183-4

[94] M. Endo, T. Takeda, Y. J. Kim, K. Koshiba and K. Ishii, "High power electric double layer capacitor (EDLC's); from operating principle to pore size control in advanced activated carbons", Carbon Science 1(3-4), 117-128 (2001).

[95] D. Qu and H. Shi, "Studies of activated carbons used in double-layer capacitors", J. Power Sources 74(1), 99-107 (1998). http://dx.doi.org/10.1016/ S0378-7753 (98) 00038-X

[96] J. P. Zheng, P. J. Cygan and T. R. Jow, "Hydrous ruthenium oxide as an electrode material for electrochemical capacitors", J. Electrochem. Soc. 142(8), 2699-2703 (1995). http://dx.doi.org/10.1149/1. 2050077

[97] D. Yu and L. Dai, "Self-assembled graphene/carbon nanotube hybrid films for supercapacitors", J. Phys. Chem. Lett. 1(2), 467-470 (2009). http://dx.doi. org/10.1021/jz9003137

[98] K. H. An, W. S. Kim, Y. S. Park, J. M. Moon, D. J. Bae, S. C. Lim, Y. S. Lee and Y. H. Lee, "Electrochemical properties of high-power supercapacitors using single-walled carbon nanotube electrodes", Adv. Funct. Mater. 11(5), 387-392 (2001). http:// $\mathrm{dx}$.doi.org/10.1002/1616-3028(200110)11: $5 \$<\$ 387$ : : AID-ADFM387\$>\$. 3. CO; $2-7$

[99] D. Stoller, S. Park, Y. Zhu, J. An and R. S. Ruoff, "Graphene-based ultracapacitors", Nano Lett. 8(10), 3498-3502 (2008). http://dx.doi.org/10. $1021 / \mathrm{nl} 802558 \mathrm{y}$

[100] Y. Zhu, S. Murali, M. D. Stoller, A. Velamakanni, R. D. Piner and R. S. Ruoff, "Microwave assisted exfoliation and reduction of graphite oxide for ultracapacitors", Carbon 48(7), 2118-2122 (2010). http://dx. doi.org/10.1016/j. carbon. 2010.02.001
[101] Y. Wang, Z. Shi, Y. Huang, Y. Ma, C. Wang, M. Chen and Y. Chen, "Supercapacitor devices based on graphene materials", J. Phys. Chem. C 113(30), 13103-13107 (2009). http://dx.doi.org/10.1021/ jp902214f

[102] B. Fuertes, F. Pico and J. M. Rojo, "Influence of pore structure on electric double-layer capacitance of template mesoporous carbons", J. Power Sources 133(2), 329-336 (2004). http://dx.doi.org/ $10.1016 / \mathrm{j}$. jpowsour. 2004.02.013

[103] C. Liu, Z. Yu, D. Neff, A. Zhamu and B. Z. Jang, "Graphene-based supercapacitor with an ultrahigh energy density", Nano Lett. 1(12), 4863-4868(2010). http://dx.doi.org/10.1021/nl102661q

[104] L. L. Zhang, R. Zhou and X. S. Zhao, "Graphenebased materials as supercapacitor electrodes", J. Mater. Chem. 20, 5983-5992 (2010). http://dx.doi. org/10.1039/c000417k

[105] L. L. Zhang, X. Zhao, M. D. Stoller, Y. Zhu, H. Ji, S. Murali, Y. Wu, S. Perales, B. Clevenger and R. S. Ruoff, "Highly conductive and porous activated reduced graphene oxide films for high-power supercapacitors", Nano Lett. 12(4), 1806-1812 (2012). http://dx.doi.org/10.1021/n1203903z

[106] Y. Han, B. Oyilmaz, Y. Zhang and P. Kim.Energy, "Band-gap engineering of graphene nanoribbons", Phys. Rev. Lett. 98(20), 206805-206808 (2007). http://dx.doi.org/10.1103/PhysRevLett. 98. 206805

[107] B. Z. Jiang and A. Zhamu, "Processing of nanographene platelets (NGPs) and NGP nanocomposites: a review", J. Mater. Sci. 43, 5092-5101 (2008). http://dx.doi.org/10.1007/ s10853-008-2755-2

[108] H. Zhang, X. Lv, Y. Li, Y. Wang and J. Li, "P25graphene composite as a high performance photocatalyst", ACS Nano 4(1), 380-386 (2010). http://dx. doi.org/10.1021/nn901221k

[109] X. Y. Zhang, H. P. Li, X. L. Cui and Y. Lin, "Graphene/ $\mathrm{TiO}_{2}$ nanocomposites: synthesis, characterization and application in hydrogen evolution from water photocatalytic splitting", J. Mater. Chem. 20, 2801-2806 (2010). http://dx.doi.org/10.1039/ b917240h

[110] G. Jiang, Z. Lin, C. Chen, L. Zhu, Q. Chang, N. Wang, W. Wei and $\mathrm{H}$. Tang, " $\mathrm{TiO}_{2}$ nanoparticles assembled on graphene oxide nanosheets with high photocatalytic activity for removal of pollutants", Carbon 49(8), 2693-2701 (2011). http://dx.doi.org/ 10.1016/j . carbon. 2011.02.059

[111] V. Štengl, S. Bakardjieva, T. M. Grygar, J. Bludská and M. Kormunda, " $\mathrm{TiO}_{2}$-graphene oxide nanocomposite as advanced photocatalytic materials", Chem. Centr. J. 7, 41-53 (2013). http://dx.doi.org/10. $1186 / 1752-153 X-7-41$

[112] A. Hu, P. Peng, H. Alarifi, X. Y. Zhang, J. Y. Guo, Y. Zhou and W. W. Duley, "Femtosecond laser welded nanostructures and plasmonic devices", J. Laser Appl. 24(4), 042001-7 (2012). http://dx.doi. org/10.2351/1.3695174 